\title{
Leukocytosis, CTCAE
}

National Cancer Institute

\section{Source}

National Cancer Institute. Leukocytosis, CT CAE. NCI Thesaurus. Code C143647.

A disorder characterized by laboratory test results that indicate an increased number of white blood cells in the blood. 